\title{
SPRAY APPLICATIONS TO TOMATO PLANTS IN GREENHOUSES. PART 2: EFFECT OF SPRAY LANCE TYPE
}

\author{
Emanuele Cerruto, Giuseppe Emma, Giuseppe Manetto
}

\section{Introduction}

A recent survey in Italy on about 200 farms [Cerruto, 2008] showed that the application of plant protection products in greenhouses is mostly performed by means of handheld high pressure spray lances or spray guns $(71 \%)$. The lances are equipped with 1 $(78 \%), 2(17 \%)$ or more $(5 \%)$ nozzles; the 77 percent are cone nozzles, the remaining 23 percent are flat fan nozzles.

The working pressures range from 2 to 40 bar, with the highest percentage (44\%) in the range 15-20 bar. The volume application rates are quite high, in most cases $(57 \%)$ in the range $1000-2000 \mathrm{~L} / \mathrm{ha}$, justified by operators with the need to spray all the foliage so to reach pathogens nested on the underside surface of the leaves.

So, even with a "simple" equipment, there is a wide variety of operating modes [Balsari 2001; Nuyttens 2005; Hughes 2008; Garrido Frenich 2002; De Vreede 1998; Bjugstgad 1996] which affect heavily quality of application, ground losses, operator safety, and environmental impact.

In this research we intend to discuss some of these aspects, namely foliar deposit, ground losses and dermal exposure of the operator, while spraying tomato plants in greenhouses by using handheld spray lances. In the first part of the research [Cerruto 2009] we discussed the effects of operator walking direction (forward vs. backwards) and plant growth stage (pre-production vs. full development). In this second part we

Paper received 20.07.2009; accepted 08.09.2009

Prof. Ing. Emanuele Cerruto, Associate Professor (ecerruto@unict.it), Dr. GiusePPE EMMA,PhD (gemma@unict.it), Dr. Ing. GIUSEPPE MANETTO, Researcher (gmanetto@unict.it). Dipartimento di Ingegneria Agraria, University of Catania, Italy.

Research developed within the 2005 PRIN project: Machinery and their adjustment for a sustainable pest control in glasshouses. report the results obtained by comparing two models of spray lance and two working pressures. The experimental tests were conducted according to a procedure very similar to that described in the first part, here briefly summarised for the sake of completeness.

\section{Materials and methods}

\subsection{The crop}

Spraying trials were carried out on full developed tomato plants, $c v$ Ikram, on June 11-12, 2007. The plants have been transplanted in twin-rows $30 \mathrm{~m}$ long, with inter-row distance of $0.60 \mathrm{~m}$, inter-twin-row distance of $1.40 \mathrm{~m}$, and row spacing of $0.35 \mathrm{~m}$. The plant density was therefore $28600 \mathrm{ha}^{-1}$.

The crop was characterised by measuring the main geometrical quantities, the Leaf Area Index (LAI), and the theoretical number of foliar layers $(n L)$. The geometrical measurements were carried out on 24 plants belonging to both rows of 12 different twin-rows. The $L A I$ was assessed by defoliating and estimating the foliar surface of 4 plants. The foliar surface was estimated by computing the regression equation of the surface on the mass, based upon a sample of 66 leaves representative of the whole plants. The foliar mass was measured by means of a precision balance, whereas the surface was measured acquiring the image of each leaf by means of a scanner and using the open source image analysis software "The Gimp". Acquiring an image of known area (A4 paper, $21.0 \times$ $29.7 \mathrm{~cm}$ ), The Gimp provided, by means of a histogram, the area fraction covered by the leaf, from which the leaf area was calculated.

Finally, the theoretical number of foliar layers was computed according to the equation:

$$
n L=\frac{a \times L A I}{\Delta h}
$$

where $a=1 \mathrm{~m}$ is the average between-rows distance and $\Delta h$ the foliage height. 


\subsection{The spray lances}

Spraying tests were carried out comparing two hand-held spray lances: a "conventional" spray lance (Figure 1), equipped with one turbulence nozzle, whose orifice diameter was $1.5 \mathrm{~mm}$, and the Yamaho C-6 spray lance (Figure 2), yet described in [Cerruto, 2009]. The latter has two steel nozzles, each with two orifices and, in accordance with the classification of the British Crop Protection Council $(B C P C)$, produces sprays ranging from fine to very fine when the pressure ranges from 10 to $20 \mathrm{bar}$.

Both spray lances were tested at 10 and 20 bar, arranging a factorial design. The effective pressure values were checked by means of a pressure gauge installed near the handle, adjusting the pump pressure so to compensate for the pressure drop of 1 bar through the $80 \mathrm{~m}$ hose-pipe.

The flow rate of both lances at each pressure value was calculated by collecting in graduates the water issuing from each nozzle and measuring the spraying time.

The $500 \mathrm{~L}$ tank, the motor pump, and the hosepipe, wound round a winding drum, were placed on a small motor-truck.

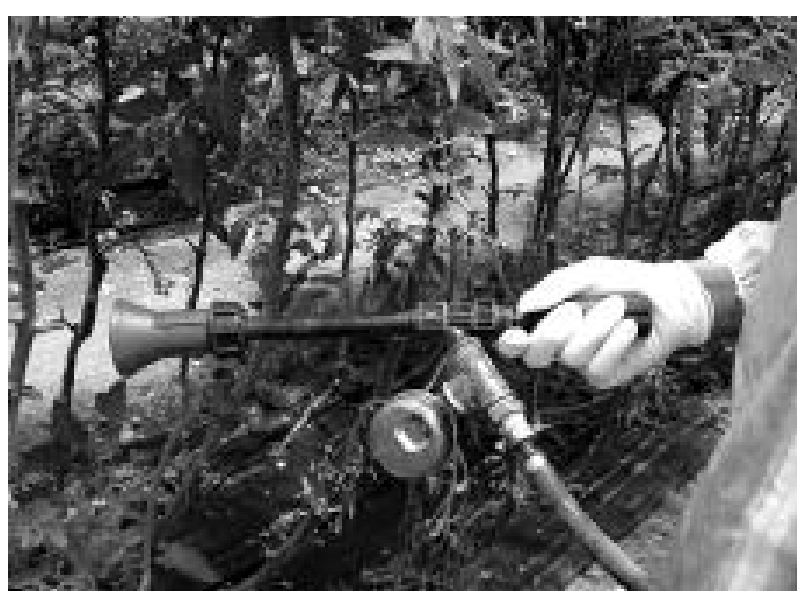

Fig. 1 - "Conventional" spray lance.

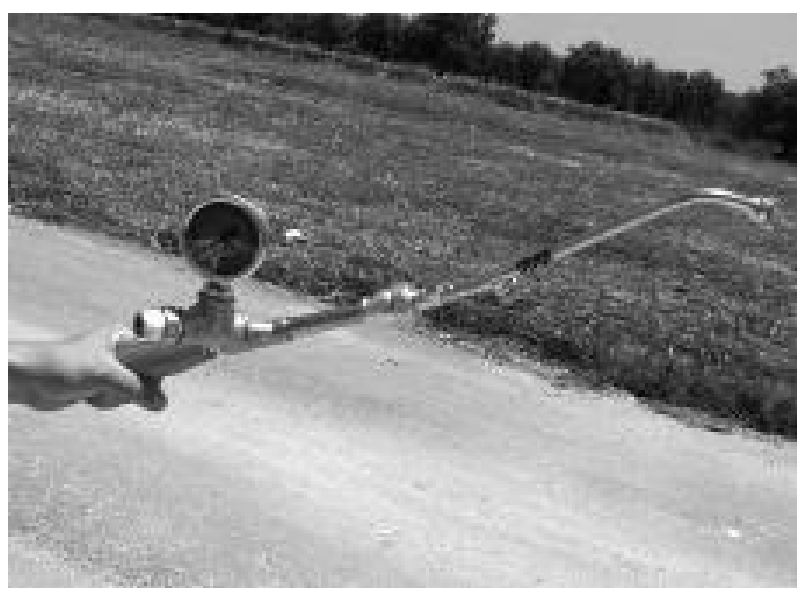

Fig. 2 - Yamaho C-6 spray lance.

\subsection{The experimental design}

The experimental tests were carried out by walking backwards, as the first year activity showed that the dermal operator exposure could be greatly reduced by performing spray applications in this operating mode walking backwards, without penalising quality of the application and ground losses. For organisational reasons, foliar deposition and ground losses were measured independently from the operator dermal exposure.

Measuring the spraying time and then calculating the walking speed, and taking into account the nozzle output and the crop layout, the experimental design was as reported in Table 1. The little difference in walking speed between the two sets of experiments was due to physiological causes of the operator.

\begin{tabular}{lrrrr}
\hline Spray lance & $\begin{array}{r}\text { Pressure, } \\
\text { bar }\end{array}$ & $\begin{array}{r}\text { Speed, } \\
\mathrm{km} / \mathrm{h}\end{array}$ & $\begin{array}{r}\text { Flow rate, } \\
\mathrm{L} / \mathrm{min}\end{array}$ & $\begin{array}{r}\text { Volume rate, } \\
\mathrm{L} / \mathrm{ha}\end{array}$ \\
\hline \multicolumn{5}{c}{ Foliar deposition and ground losses } \\
\hline Yamaho-C6 & 10 & 2.7 & 3.5 & 775 \\
Yamaho-C6 & 20 & 2.7 & 5.1 & 1123 \\
Conventional & 10 & 2.7 & 4.0 & 890 \\
Conventional & 20 & 2.7 & 5.6 & 1252 \\
\hline \multicolumn{5}{c}{ Dermal operator exposure } \\
\hline Yamaho-C6 & 10 & 3.0 & 3.5 & 698 \\
Yamaho-C6 & 20 & 3.0 & 5.1 & 1010 \\
Conventional & 10 & 3.0 & 4.0 & 801 \\
Conventional & 20 & 3.0 & 5.6 & 1127 \\
\hline
\end{tabular}

TABLE 1 - Experimental design.

The experimental trials consisted in spraying, under standard field conditions, a water solution with $2 \%$ of food dye red Poinceau as a tracer and $0.05 \%$ of a surfactant. Three replicates were carried out for each treatment, arranged according to a randomised block design. Each block consisted in two twin-rows $30 \mathrm{~m}$ long, alternated with three unsprayed twin-rows so to avoid overlapping of deposits during replicates and treatments. The chosen twin-rows were split in two equal parts and each part was sprayed on both rows according to the experimental design, walking in the spaces between the twin-rows.

\subsection{Foliar deposition measurement}

Like in the first year activity, leaf sampling was carried out on both rows (left and right) of the sprayed twin-rows. Based upon the geometrical measurements, the canopy was divided up into three equal height zones (low, middle, and high) and into two depth layers (external and internal). After mixture application, 4 leaves were randomly picked on each of these 12 sampling zones $(3$ heights $\times 2$ depths $\times 2$ rows), totalling 48 leaves/replicate and then 144 leaves/treatment and 576 total leaves.

The foliar deposit was measured by means of a spectrophotometric technique and, to allow compar- 
isons among the treatments, all values were normalised to a fixed volume rate of $1000 \mathrm{~L} / \mathrm{ha}$, roughly the average value of the applied volume rates.

\subsection{Ground losses and operator exposure measurement}

Ground losses were measured by means of collectors (10 per replicate) consisting in whole Petri dishes (base and top, whose diameters were $147 \mathrm{~mm}$ and 151 $\mathrm{mm}$ respectively, and then the area $169.6 \mathrm{~cm}^{2}$ and $179.0 \mathrm{~cm}^{2}$ ), arranged in two rows, $3 \mathrm{~m}$ spaced, across the sprayed twin-rows (Figure 3 ). The measurements were carried out in the same way as the deposit on leaves had been measured and the values for each replicate were expressed both as unitary deposit and fraction of the applied volume rates. The latter was computed by weighing the deposits in each position, being the weights the widths of the sampled area.

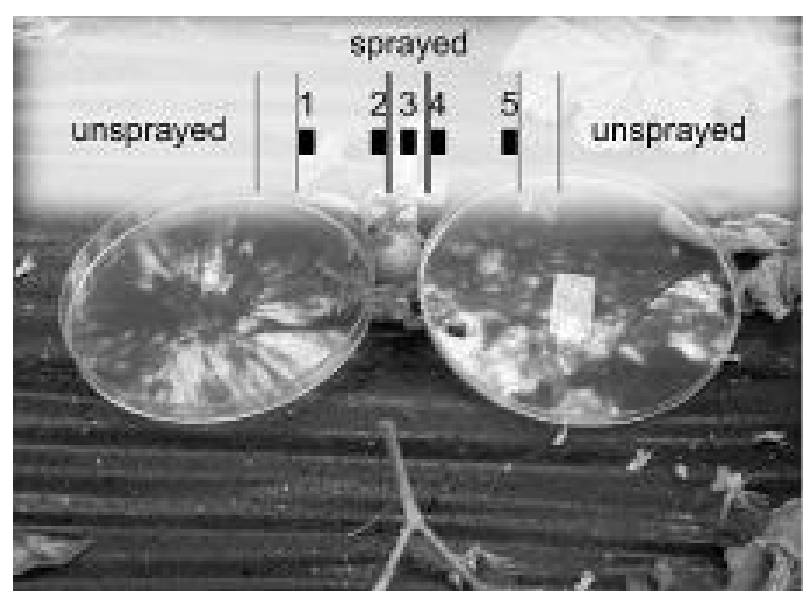

Fig. 3 - Collectors to measure the ground losses.

In order to measure the dermal exposure, the operator sprayed a $60 \mathrm{~m}$ path $(30 \mathrm{~m}$ outward and $30 \mathrm{~m}$ return) between two twin-rows. He was wearing a polypropylene disposable overall (Green Bay), completed with cover-shoes, respirator, and latex gloves. Three replicates per treatment were carried out.

After each replicate, the overall was cut in several pieces and the exposure of each piece was again measured by means of the spectrophotometric technique. It was expressed both as unitary deposit (microlitres per square centimetre per working hour) and as millilitres per working hour. To account for the differences in the volume application rates, the values were normalised to $1000 \mathrm{~L} / \mathrm{ha}$.

\subsection{Data analysis}

All data (normalised foliar deposits, fraction of the applied volume rate on the ground, and millilitres of mixture collected by the operator' body per working hour) were analysed by means of the analysis of variance (ANOVA) to detect statistically significant dif- ferences due to the spray lance type or the working pressure. When necessary, the data were transformed to normalise the distribution of the residuals and to make constant their variance, so to meet the prerequisites for the ANOVA application.

All computations and graphical representations were performed by means of the open source software $R$ [R development Core Team 2007].

\section{Results and discussion}

\subsection{Plant features}

Table 2 reports the main geometrical and morphological quantities of the plants.

\begin{tabular}{lcc}
\hline \multicolumn{3}{c}{ Geometrical quantities } \\
\hline Features & Mean, $\mathrm{m}$ & $\mathrm{CV}, \%$ \\
\hline Minimum height & 0.83 & 26 \\
Maximum height & 2.45 & 8 \\
Width at 0.95 m & 0.45 & 33 \\
Width at $1.45 \mathrm{~m}$ & 0.58 & 30 \\
Width at $1.95 \mathrm{~m}$ & 0.63 & 28 \\
\hline \multicolumn{2}{c}{ Morphological quantities } \\
\hline Sampling area, m & LAI, $\mathrm{m}^{2} / \mathrm{m}^{2}$ & $n L$ \\
\hline Low (0.83-1.37) & 0.27 & 0.5 \\
Middle (1.37-1.91) & 0.77 & 1.4 \\
High (1.91-2.45) & 1.95 & 3.6 \\
Total (0.83-2.45) & 2.99 & 1.8 \\
\hline
\end{tabular}

TABLE $2-$ Main features of the foliage to be sprayed.

Based upon these geometrical measurements, the three equally spaced height zones were about $0.55 \mathrm{~m}$ wide and started at about $0.80 \mathrm{~m}$ from the ground.

The study of the regression of foliar surface $(S$, $\left.\mathrm{cm}^{2}\right)$ on foliar mass $(\mathrm{m}, \mathrm{g})$ produced the relationship:

$$
S=38.0798 \cdot m^{0.6989}
$$

Its graphical representation, on log-log scale, is reported in Figure 4. The determination coefficient $R^{2}=$ 0.910 was highly significant $(p$-level $<0.001)$. Based on this equation, Table 2 also reports $L A I$ and number of foliar layers of the plants.

\subsection{Foliar deposition}

The analysis of variance of the foliar deposits normalised to $1000 \mathrm{~L} / \mathrm{ha}$ produced the results summarised in Table 3, interrupted at the main factors and the first interaction terms, being all higher interaction terms not statistically significant. The data were logtransformed to properly apply the ANOVA.

Among the main factors, only height and depth produced statistically significant differences on the deposits, even if affected by pressure (pressure $\times$ depth interaction significant at $p$-level $=0.002$ ) and, 


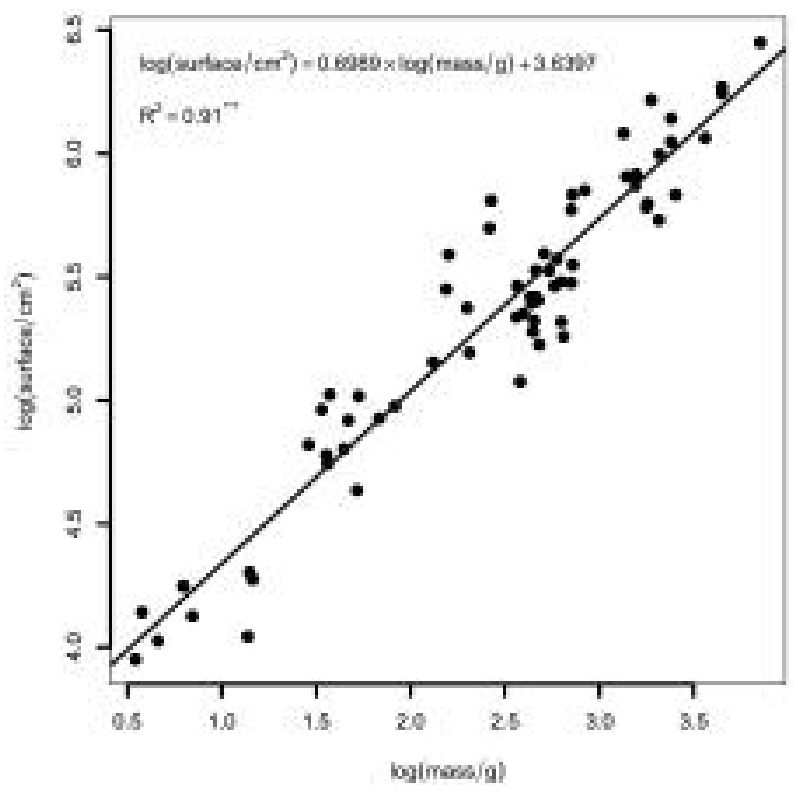

Fig. 4 - Regression of foliar surface on foliar mass.

\begin{tabular}{llll}
\hline Source & $p$-level & Source & $p$-level \\
\hline lance & 0.241 & lance $\times$ height & 0.188 \\
pressure & 0.101 & pressure $\times$ height & 0.400 \\
lance $\times$ pressure & 0.737 & row $\times$ height & 0.126 \\
row & 0.717 & lance $\times$ depth & 0.060 \\
height & $0.005^{* *}$ & pressure $\times$ depth & $0.002^{* *}$ \\
depth & $0.000^{* * *}$ & row $\times$ depth & 0.600 \\
lance $\times$ row & 0.242 & height $\times$ depth & $0.000^{* * *}$ \\
pressure $\times$ row & 0.408 & & \\
\hline
\end{tabular}

TABLE 3 - ANOVA of the normalised foliar deposits.

closely, by spray lance type (lance $\times$ depth interaction significant at $p$-level $=0.060$ ). The higher deposits produced by the Yamaho $C$ - 6 spray lance (1.23 $\left.\mu \mathrm{L} / \mathrm{cm}^{2}\right)$ with respect to the conventional one $(1.05$ $\left.\mu \mathrm{L} / \mathrm{cm}^{2}\right)$, as well as by the pressure of 20 bar $(1.21$ $\left.\mu \mathrm{L} / \mathrm{cm}^{2}\right)$ vs. 10 bar $\left(1.07 \mu \mathrm{L} / \mathrm{cm}^{2}\right)$, were not statistically significant. The differences between the two rows of the twin-rows $\left(1.12 \mu \mathrm{L} / \mathrm{cm}^{2}\right.$ vs. $\left.1.15 \mu \mathrm{L} / \mathrm{cm}^{2}\right)$ were more reduced, being the two rows equally sprayed. The average values of the deposits for each level of the main factors are reported in Figure 5.

Analysing the deposition with reference to the height factor, the highest deposits were measured on average in the middle zone of the canopy, whereas the lowest were measured in the low zone (where the small foliar density - Table 2 - prompted the operator to reduce the treatment time), and in the high zone (because of the higher $L A I$ ).

On average, the deposit on the external layer was 60 percent greater than that on the internal layer (1.40 $\mu \mathrm{L} / \mathrm{cm}^{2}$ vs. $0.88 \mu \mathrm{L} / \mathrm{cm}^{2}$ ), but this result was affected by the sampling height (height $\times$ depth interaction significant at $p$-level $<0.001)$. Precisely, the differences between external and internal layer were located in the high and middle zones (Table 4), where the LAI

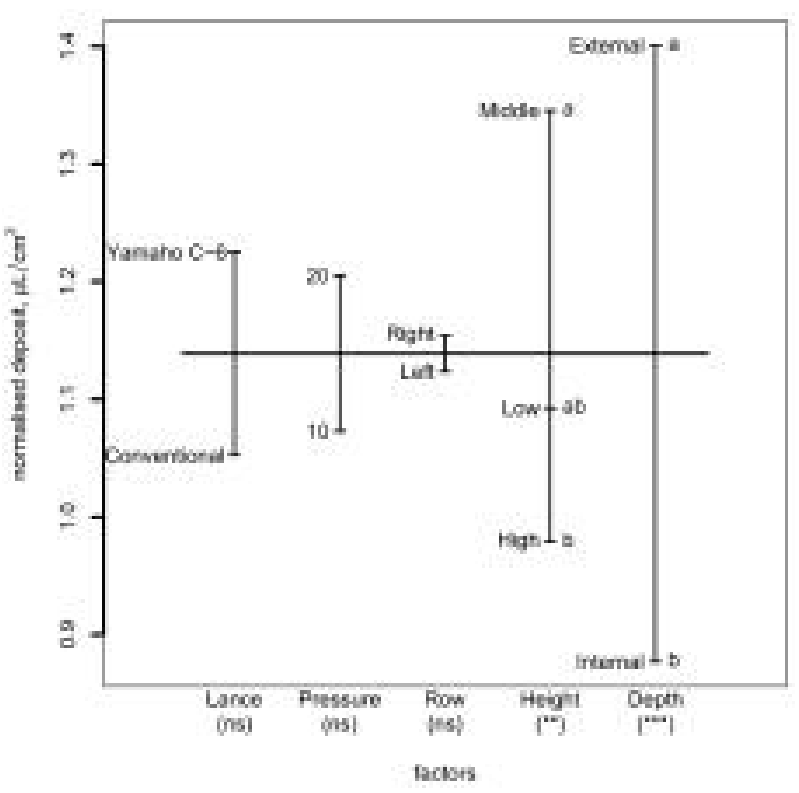

Fig. 5 - Plot design of the experimental trials (mean separation by HSD Tukey test at $5 \%$ level).

\begin{tabular}{llccc}
\hline Layer & Low & Middle & High & Mean \\
\hline External & $1.04^{\mathrm{a}}$ & $1.77^{\mathrm{a}}$ & $1.39^{\mathrm{a}}$ & $1.40^{\mathrm{a}}$ \\
Internal & $1.14^{\mathrm{a}}$ & $0.92^{\mathrm{b}}$ & $0.57^{\mathrm{b}}$ & $0.88^{\mathrm{b}}$ \\
Mean & $1.09^{\mathrm{ab}}$ & $1.35^{\mathrm{a}}$ & $0.98^{\mathrm{b}}$ & 1.14 \\
\hline
\end{tabular}

TABLE 4 - Normalised deposits $\left(\mu \mathrm{L} / \mathrm{cm}^{2}\right)$ on the three height zones and on the two depth layers (mean separation by HSD Tukey test at 5\% level).

was higher than in the low zone. This result demonstrates the difficulties of the spray jet to penetrate inside canopies with high foliar density. Therefore an air assisted treatment with a small fan for moving the leaves should increase the uniformity of the deposits.

Also the working pressure influenced significantly the deposits with respect to the sampling depth. The interaction is plotted in Figure 6, where the effect of the spray lance type is also highlighted.

On average, from 10 to 20 bar, the normalised deposit on the internal layer showed a significant percentage increase $\left(+57.2 \%\right.$, from $0.68 \mu \mathrm{L} / \mathrm{cm}^{2}$ to 1.07 $\left.\mu \mathrm{L} / \mathrm{cm}^{2}\right)$, while the percentage decrease $(-8.6 \%$, from $1.46 \mu \mathrm{L} / \mathrm{cm}^{2}$ to $1.33 \mu \mathrm{L} / \mathrm{cm}^{2}$ ) on the external layer was not statistically significant. This means that the higher kinetic energy of the spray jet at 20 bar improves its penetration inside the canopy, without penalising significantly the deposition on the external layer.

This behaviour is more evident with the conventional spray lance which, being equipped with 1 nozzle with 1 orifice, produces, with respect to the Yamaho $C$-6 lance, bigger drops with higher kinetic energy. As a consequence, it produced the same foliar deposit on both external and internal layer at 20 bar: 1.16 $\mu \mathrm{L} / \mathrm{cm}^{2}$ and $1.13 \mu \mathrm{L} / \mathrm{cm}^{2}$, respectively. 


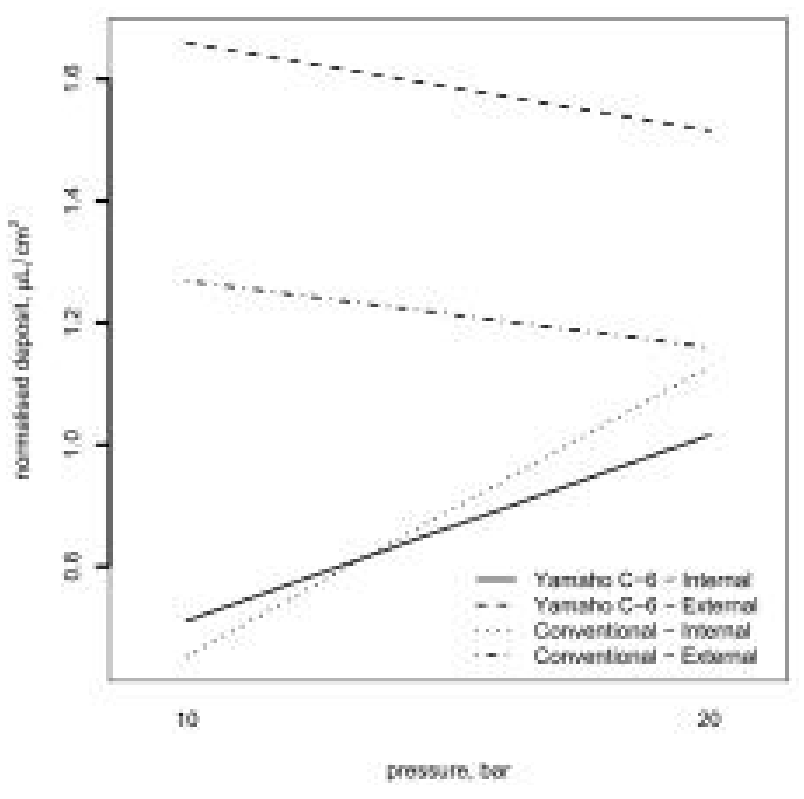

Fig. 6 - Normalised deposits vs. pressure, depth and lance type.

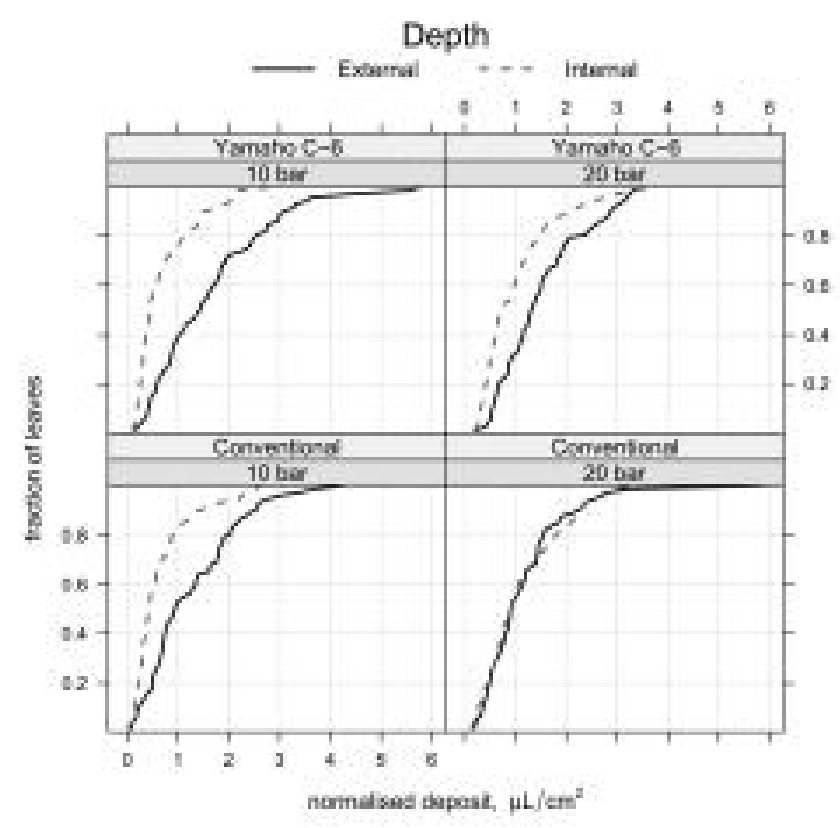

Fig. 7 - Normalised foliar deposit at the two depth layers, varying spray lance and working pressure.

Finally, looking at the spray lance $\times$ depth interaction, while on the internal layer both spray lances produced the same foliar deposit, on the external layer the Yamaho $C-6$ produced a significantly higher deposit. This because the Yamaho $C-6$ spray jet, split in two parts by the two nozzles, each with two orifices, along with a finer pulverisation, ensures a greater deposition.

This may be visually assessed by inspecting Figure 7, where are reported the cumulative distribution functions of the normalised deposits produced by each spray lance on the two depth layers at the two working pressures. It may be observed that on the external layer the fraction of leaves with low deposits when using the conventional spray lance was higher than that measured with the Yamaho $C-6$ spray lance. This was more evident when the working pressure increased from 10 to 20 bar, but in this case the normalised deposit produced by the conventional lance was the same on both layers, showing a better capacity of the jet issuing from this spray lance of penetrating into the canopy.

\subsection{Ground losses}

On average, the ground losses amounted to about one fourth $(25.2 \%)$ of the applied volume rate and were significantly influenced only by the pressure ( $p$ level $=0.048)$. The fraction of the applied volume on the ground increased from 21.7 to 28.7 percent changing the working pressure from 10 to 20 bar.

Looking at more in depth the results, the ANOVA of the normalised deposits measured on the Petri dishes (Table 5) showed that they were significantly influenced by lance, pressure, and position (lance $\times$ pressure $\times$ position interaction significant at $p$-level $=$ 0.012).

The highest normalised deposits (Figure 8), for both pressures and spray lances, were measured in the positions 2, 3 and 4 (Figure 3), under the sprayed twin-row. But, while the Yamaho $C$ - 6 spray lance produced comparable normalised deposits with both pressures, the conventional lance produced significantly higher deposits in positions 2,3 , and 4 at 20

\begin{tabular}{llll}
\hline Source & $p$-level & Source & $p$-level \\
\hline lance & 0.793 & lance $\times$ pressure & 0.247 \\
pressure & $0.044^{*}$ & lance $\times$ position & $0.000^{* * *}$ \\
position & $0.000^{* * *}$ & pressure $\times$ position & 0.188 \\
& & lance $\times$ pressure $\times$ position & $0.012^{*}$ \\
\hline
\end{tabular}

TABLE 5 - ANOVA of the ground losses.

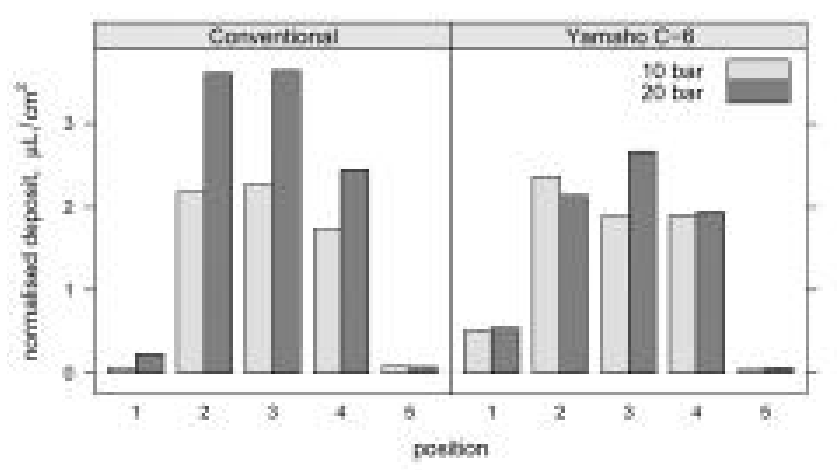

Fig. 8 - Normalised deposit on the five measuring positions across the sprayed rows. 
bar with respect to 10 bar. This confirms the idea that the conventional spray lance, with this regulation, releases drops with high inertia that do not adhere on the leaf surface and fall on the ground when spraying the low zone of the canopy.

\subsection{Operator exposure}

The ANOVA showed that the whole dermal operator exposure was significantly affected neither by the spray lance type nor by the working pressure. The lower exposure measured with the Yamaho $C-6$ spray lance, especially at 20 bar (Table 6), when one replicate produced very low values, was not statistically significant. On average, with a reference volume of $1000 \mathrm{~L} / \mathrm{ha}$, the exposure on the operator's body was $39.5 \mathrm{~mL} / \mathrm{h}$ of mixture. This value approximately confirms the results obtained in the course of the first year, when the exposure, walking backwards and spraying $1800 \mathrm{~L} / \mathrm{ha}$, was $46.9 \mathrm{~mL} / \mathrm{h}$.

\begin{tabular}{lccc}
\hline Lance & 10 bar & 20 bar & Mean \\
\hline Conventional & 49.71 & 48.83 & 49.27 \\
Yamaho C-6 & 45.99 & 13.57 & 29.78 \\
Mean & 47.85 & 31.20 & 39.52 \\
\hline
\end{tabular}

TABLE 6 - Dermal operator exposure $(\mathrm{mL} / \mathrm{h})$.

Analysing the exposure level found in each one of the body parts (Figure 9), the left arm was the most exposed area: in fact, it accounted for 39 percent of the whole exposure. The second most exposed area was the back, with almost 10 percent. These results are in accordance with the operating mode: in fact the operator, holding the spray lance in his or her right hand, spraying the row on his or her right side, and walking backwards, brushed back and left arm against the sprayed row in the course of the return path inside an inter-row between two twin-rows.

The other body parts, except for the respirator, which accounted for 2 percent, showed comparable exposure levels, ranging from 4 to 7 percent of the whole exposure.

Collecting the pieces of the overall in homogeneous groups, more than 50 percent of the total exposure was found in the upper limbs, whereas the lower limbs and the other parts of the body (head and trunk) accounted for the same percentage (24\%).

Looking at the unitary deposits, the mean value, weighted according to the surface of the overall, amounted to $1.19 \mu \mathrm{L} /\left(\mathrm{cm}^{2} \mathrm{~h}\right.$ ) (Figure 10$)$, with little differences between the spray lances (Conventional: $1.48 \mu \mathrm{L} /\left(\mathrm{cm}^{2} \mathrm{~h}\right)$; Yamaho $\left.C-6: 0.90 \mu \mathrm{L} /\left(\mathrm{cm}^{2} \mathrm{~h}\right)\right)$ and the working pressures (10 bar: $1.44 \mu \mathrm{L} /\left(\mathrm{cm}^{2} \mathrm{~h}\right) ; 20$ bar: $\left.0.94 \mu \mathrm{L} /\left(\mathrm{cm}^{2} \mathrm{~h}\right)\right)$.

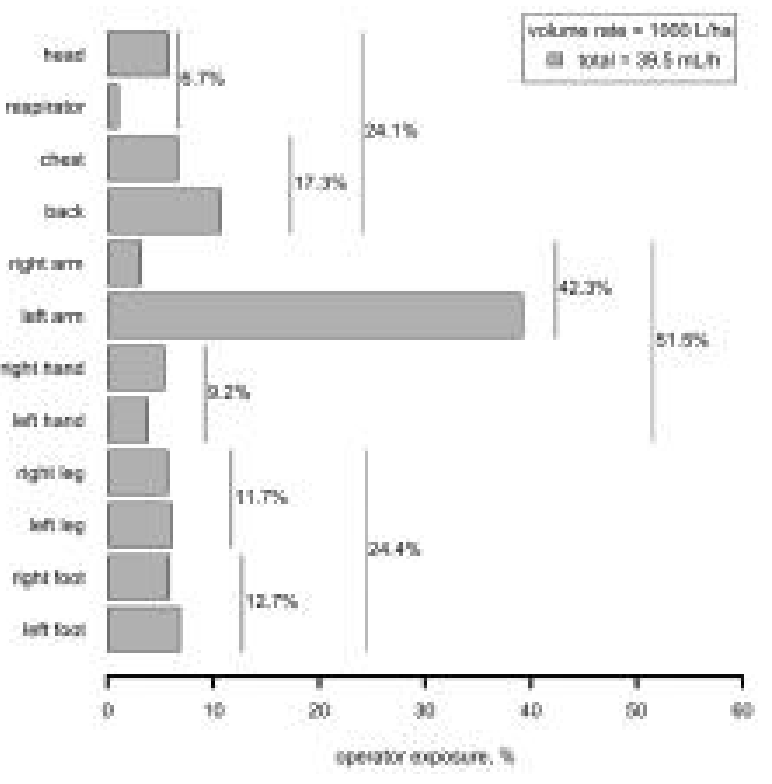

Fig. 9 - Exposure subdivision among the body's parts.

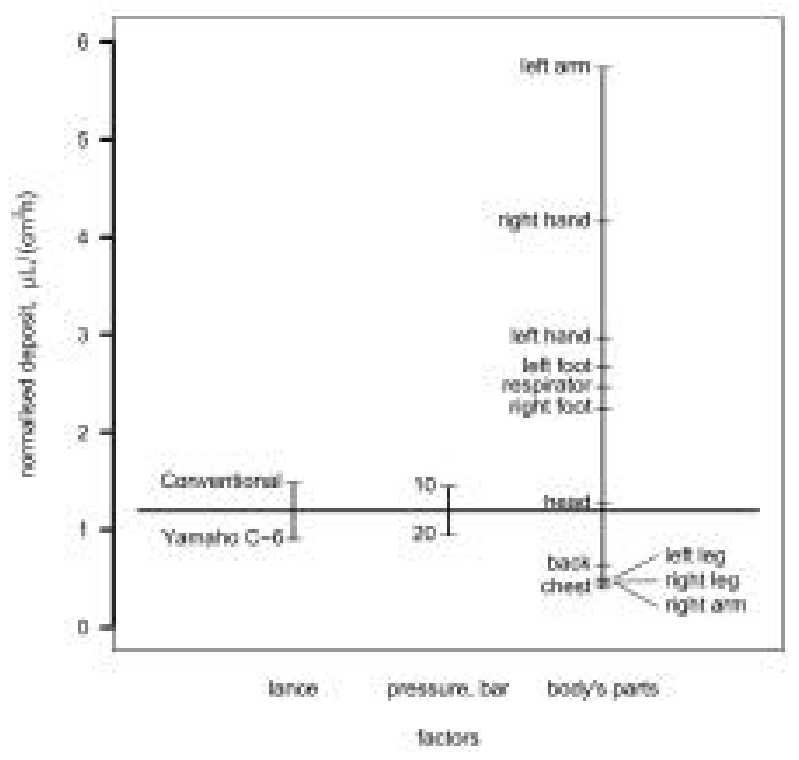

Fig. 10 - Weighted unitary deposit on the body's parts.

Big differences were instead measured among the body's parts. The greatest unitary deposit was again measured on the left arm $\left(5.73 \mu \mathrm{L} /\left(\mathrm{cm}^{2} \mathrm{~h}\right)\right)$, followed by the right hand, that was holding the spray lance $\left(4.16 \mu \mathrm{L} /\left(\mathrm{cm}^{2} \mathrm{~h}\right)\right)$. As the deposit on the respirator was also relatively high $\left(2.47 \mu \mathrm{L} /\left(\mathrm{cm}^{2} \mathrm{~h}\right)\right)$, these results should convince operators to protect one's body by wearing proper personal protective equipment (overall, gloves, and mask).

\section{Conclusions}

The experimental tests allow for the following conclusions: 
- Neither spray lance type nor working pressure affected significantly the average foliar deposition. However, the pressure influenced significantly the penetration of the spray jet into the canopy: on average, the foliar deposits on the internal layer had an increase of 57 percent when the pressure rose from 10 to 20 bar. Also the spray lance type influenced the foliar deposition on the two depth layers ( $p$-level = 0.06): in fact, the conventional spray lance produced the same foliar deposition on both layers when working at $20 \mathrm{bar}$, while the Yamaho $C-6$ produced on the internal layer as much deposit as the conventional spray lance, but a higher deposit on the external layer at any pressure. Therefore we suppose that an air-assisted system should improve the uniformity of deposition when using the Yamaho C-6 spray lance.

- Ground losses were affected significantly only by the pressure value: they increased from 21.7 to 28.7 percent when the pressure increased from 10 to 20 bar. They were mainly located under the sprayed twin-rows, where the conventional spray lance, due to the characteristics of its spray jet, produced the highest unitary deposits at 20 bar. On the contrary, the Yamaho $C-6$ spray lance produced similar patterns at both pressures.

- The dermal exposure of the operator was unaffected by pressure and lance type. Probably the best way to reduce the operator exposure when using spray lances, as showed in the first year activity [Cerruto, 2009] and reported by [Nuyttens, 2005], is to perform spray applications by walking backwards rather than forward.

- The body parts more exposed were the left arm, due to its brushing against the sprayed plants, and the hands, particularly the right one, which was holding the spraying equipment. Taking also into consideration the relatively high deposit on the respirator, we recommend operators to protect one's body by wearing proper personal protective equipment in any circumstance.

All things considered, we believe that the Yamaho $C$-6 spray lance, thanks to the two nozzles with higher turbulence and finer pulverisation, produced better results. Other aspects should be analysed, mainly the improvements of the uniformity of the deposits inside the canopy by using an air-assisted system and the measurement of the deposit on both leaf surfaces.

\section{References}

Balsari P., Oggero G., Comparison among Different Types of Spray Application Equipment in Greenhouses, Proceedings on CD-ROM of the AIIA 2001, Vieste (Fg), Italy, September 11-14, 2001.

Bjugstad N., Torgrimsen T., Operator Safety and Plant Deposits when using Pesticides in Greenhouses, J. Agric. Engng. Res., 1996, 65, 205-212.

Cerruto E., Balsari P., Oggero G., Friso D., Guarella A., Raffaelli M., Operator Safety during Pesticide Applica- tion in Greenhouses: a Survey on Italian Situation, GreenSys 2007, Naples, Italy, October 4-6, 2007, ISHS Acta Horticulturae 801, November 25, 2008, Vol. 2, 1507-1514.

Cerruto E., Emma G., Manetto G., Spray Application to Tomato plants in Greenhouses. Part 1: Effect of Walking Direction, Journal of Agricultural Engineering, 2008, 3, 41-48.

De Vreede J.A.F., Brouwer D.H., Stevenson H., Van Hemmen J.J., Exposure and Risk Estimation for Pesticides in High-Volume Spraying, Ann. Occup. Hyg., 1998, Vol. 42, No. 3, 151-157.

Garrido Frenich A., Aguilera P.A., Egea Gonzalez F., Castro Cano M.L., Martinez Galera M., Martinez Vidal J.L., Soler M., Dermal Exposure to Pesticides in Greenhouses Workers: Discrimination and Selection of Variables for the Design of Monitoring Programs, Environmental Monitoring and Assessment, 2002, 80, 51-63.

Hughes E.A., Flores A.P., Ramos L.M., Zalts A., Glass C.R., Montserrat J.M., Potential Dermal Exposure to Deltamethrin and Risk Assessment for Manual Sprayers: Influence of Crop Type, Science of the Total Environment, 2008, 391, 34-40.

Nuyttens D., Windey S., Sonck B., Comparison of Operator Exposure for five different Greenhouse Spraying Applications, XXXI CIOSTA-CIGR V Congress "Increasing Work Efficiency in Agriculture, Horticulture and Forestry", September 19-21, 2005, University of Hohenheim, Stuttgart, Germany, 98-105.

$\mathrm{R}$ Development Core Team, R: A Language and Environment for Statistical Computing, R Foundation for Statistical Computing, Vienna, Austria, ISBN 3-900051-07-0, 2007, URL http://www.R-project.org.

\section{SUMMARY}

The present paper reports the results of some spray application trials carried out in a greenhouse with full developed tomato plants to assess foliar deposition, ground losses, and dermal operator exposure when using handheld high pressure spray lances and when walking backwards during treatments. Two spray lance types (conventional with one nozzle and Yamaho $C-6$ with two steel nozzles, each with two orifices) and two working pressures (10 and 20 bar) were taken into consideration.

An experimental design with two factors (spray lance and pressure) was adopted, arranged according to a randomised block design with three replicates. Volume application rates ranged from 775 up to 1252 $\mathrm{L} / \mathrm{ha}$, but all data were normalised to $1000 \mathrm{~L} / \mathrm{ha}$.

The results showed no statistically significant differences in the mean foliar deposition between the two spray lances and the two working pressures. However, the higher pressure improved significantly the deposit into the internal layer of the canopy $(+57 \%)$, whereas the Yamaho $C-6$ spray lance produced a higher deposit on the external layer at any pressure. The greatest differences between external and internal layer were mainly concentrated in the middle and high parts of the canopy, where there were 
the highest values of $L A I$ and number of foliar layers.

The fraction of the applied volume rate on the ground was on average 25 percent and it was affected only by the pressure value: it increased from 21.7 to 28.7 percent when the pressure increased from 10 to 20 bar, due mainly to the contribution of the conventional spray lance under the sprayed twin-rows.

Finally, neither pressure nor spray lance type affected significantly the dermal operator exposure. Up- per limbs accounted for 51 percent of the total exposure, while trunk and lower limbs accounted for 24 percent each. The body parts more exposed were the left arm and the hands, but also relatively high was the deposit on the respirator, so operators should ever wear appropriate personal protective equipment.

Keywords: Pesticide, Foliar deposition, Ground losses, Operator exposure. 